\section{TERCEIRIZAÇÃO NAS INSTITUIÇÕES FEDERAIS DE ENSINO SUPERIOR: A ECONOMIA NAS CONTRATAÇÕES DE SERVIÇOS TERCEIRIZADOS NA UNIVERSIDADE FEDERAL DE PERNAMBUCO}

\author{
OUTSOURCING IN FEDERAL INSTITUTIONS OF HIGHER \\ EDUCATION: THE ECONOMY IN CONTRACTING OUTSOURCED \\ SERVICES AT THE FEDERAL UNIVERSITY OF PERNAMBUCO
}

Jose de Arimathea Cabral

Marcos Roberto Gois de Oliveira Macedo
1

Mestre em Gestão Pública para o Desenvolvimento do Nordeste pela Universidade Federal de Pernambuco (2018), possui graduação em Ciências Econômicas pela Universidade Católica de Pernambuco (1995). 2

Doutor em Economia pela Universidade Federal de Pernambuco (2005) com estágio doutorado na Université Pantheon-Sorbonne ,possui graduação em Engenharia Mecânica pela Universidade Federal de Pernambuco (1996), mestrado em Administração pela Universidade Federal de Pernambuco (2000).
Resumo:Na Administração Pública, a maioria dos seus serviços acessórios é executada por empresas contratadas por licitação, cujas regras podem elevar o risco de sobrepreços nos contratos e para evitar esse risco, as contratações públicas são planejadas, o serviço a ser contratado é detalhado e seu valor é estimado com base em pesquisas de preços, realizadas no portal de compras do governo Federal, em contratações similares de órgãos públicos ou com fornecedores do ramo do objeto a ser contratado. O objetivo desse trabalho foi mensurar a economia auferida nas contratações da UFPE, com contratos vigentes em 2017 e para isso, valeu-se da pesquisa documental e bibliográfica, analisando os processos das contratações terceirizadas, com uso exclusivo de mão de obra, tendo como resultado a economia de $\mathrm{R} \$ 11,308$ milhões, e que, a maioria dessas contratações apresentaram índice de economia na faixa de $15 \%$ a $30 \%$ do valor estimado.

palavras - chave: Gestão Pública. Contratação. Serviços. Universidades.

ABSTRACT: In the Public Administration, most of its ancillary services are executed by companies contracted by bidding, whose rules may increase the risk of over-pricing in contracts and to avoid such risk, public contracting is planned, the service to be contracted is detailed and its value is estimated based on price surveys conducted on the Federal Government procurement portal, on similar hiring of public agencies or with suppliers of the object to be hired. The objective of this work was to measure the economy obtained in the contracting of UFPE, with contracts in force in 2017 and for this, used the documentary and bibliographic research, analyzing the processes of contracted outsourced, with exclusive use of labor, resulting in the economy of R \$ 11,308 million, and that, most of these hirings presented an index of economy in the range of $15 \%$ to $30 \%$ of the estimated value.

KEYwords: Public Management. Hiring. Services. Universities 


\section{INTRODUÇÃO}

As contratações públicas seguem a lógica e o senso comum, que é buscar alternativas para atender as necessidades coletivas ao menor custo possível, em obediência aos princípios da eficiência e da economicidade, entretanto tais regras são contrariadas pelo que se pratica no mercado. No entendimento de Zagatto (2015), as Instruções Normativas do Ministério do Planejamento, com referências de produtividade e de custo, a respeito da contratação de serviços, elevam o risco de sobre-preço nos contratos.

A partir da reforma administrativa no setor público brasileiro, que se iniciou com a publicação do Decreto n⿳0 200/67 (OLHER; COSTA; TEIXEIRA, 2015) e que, segundo Sirelli (2009), obteve êxito com a Reforma do Estado, implantada no governo FHC (1994-2002), a Administração Pública tem quase todos os seus serviços acessórios e de apoio executados por empresas terceirizadas.

Segundo Zagatto (2015), é regra terceirizar essas atividades. Ele cita o crescimento do mercado de limpeza profissional que, a partir de 2009, vem crescendo a uma taxa aproximada de $10 \%$ ao ano, onde o Poder Público é responsável por $60 \%$ dessa demanda. Ainda de acordo com ele, em 2014 o Governo Federal gastou R\$ 2,4 bi com serviços de limpeza e conservação e esse valor, em termos comparativos, corresponde a 30\% do Orçamento do Ministério dos Transportes para o ano de 2015.

Os gastos com as contratações públicas são relevantes e não devem ser tratados com amadorismo. Neste sentido, a Instrução Normativa 05/2017, de 25 de maio de 2017, estabelece o Planejamento da Contratação, para cada serviço, e que deve ser realizado nas seguintes etapas: estudos preliminares, gerenciamento de riscos e termo de referência ou projeto básico.

No planejamento da contratação podem ser fixadas regras de maneira a evitar o risco da proposta inexequível. Na sessão pública do Pregão, como Zagatto (2015) explica, empresas aventureiras e despreparadas, abaixam, sem rigor, seus lances para ganhar o certame. E mesmo havendo, nas normas de licitação, dispositivos que desclassificam propostas inexequíveis, na prática é difícil desclassificar estas empresas, em razão da inexistência de indicadores de produtividade objetivos que funcionam para abrandar esse risco.

Assim, na ausência de indicadores de produtividade para o serviço a ser contratado, a Administração pode fixar postos de serviços com o quantitativo de mão de obra, cabendo às empresas preencher planilhas com os custos para pagamento dessa mão de obra, o que implica certo rigor nas disputas dos lances para vencer o certame do Pregão Eletrônico, modalidade de licitação utilizada pela Administração Pública Federal para contratar o fornecimento de bens e serviços.

Na etapa do Termo de Referência, além de detalhar o serviço a ser contratado, o valor estimado da contratação é definido com base em pesquisa de preços, nos termos da Instrução Normativa $n^{0} 5$, de 
27 de junho de 2014, realizada com a utilização de um dos seguintes parâmetros, observando a ordem de preferência, a seguir: I - no Painel de Preços disponível no endereço eletrônico http://paineldeprecos.planejamento.gov.br; II - em contratações similares de outros órgãos públicos; III - em pesquisa publicada em mídia especializada ou IV - em pesquisa com os fornecedores do ramo do objeto a ser contratado. Uma vez definido o valor estimado da contratação, a reserva orçamentária deve ser providenciada, de modo que a Administração possa planejar os seus gastos e viabilizar a execução das despesas futuras.

É notório que a Administração Pública tem um papel fundamental na sociedade, que é satisfazer os anseios da coletividade e atender aos interesses coletivos. Neste sentido, a pesquisa, através do referencial teórico, buscou levantar conceitos e definições sobre Administração Pública e instrumentos criados para tornar realidade a sua finalidade. Dentre esses instrumentos está a licitação, que é um procedimento administrativo, instituída pela Constituição Federal, e utilizada para adquirir produtos ou serviços necessários para o desempenho das atividades do setor público.

Por imposição legal, as contratações públicas devem ser realizadas através do processo de licitação cujo vencedor é aquele que apresentar a proposta mais vantajosa para a Administração e, na maioria das vezes, a proposta vencedora é aquela de menor valor. Portanto, se Administração firmou contrato com a empresa que apresentou sua proposta com menor valor, é certo que houve um ganho para as contas públicas e que deve ser mensurado.

Desse modo, o presente estudo pretende comparar o valor estimado, no planejamento da contratação de serviços terceirizados, com o que foi efetivamente contratado. E como se tratam de serviços de natureza continuada, os seus contratados são renovados, por períodos sucessivos até o limite definido em lei, podendo haver repactuação nos valores inicialmente contratados e esses reajustes também serão objetos desse estudo.

Para chegar ao objetivo deste trabalho, valeu-se da característica da pesquisa documental, e foram analisados processos e atas dos pregões destinados a selecionar empresas especializadas nas prestações de serviços, consultando os arquivos da Diretoria de Licitações e Contratos da Pró Reitoria de Gestão Administrativa da UFPE (DLC/ PROGEST) e o Portal de Compras do Governo Federal, disponível na Internet, através do site www.comprasnet.gov.br.

A coleta de dados consistiu na primeira fase em listar os contratos de serviços terceirizados com dedicação exclusiva de mão de obra, vigentes no ano 2017, registrando qual a licitação em que estava vinculado, passando a seguir o procedimento de consulta ao site de compras do governo federal, onde foram analisadas as atas dos processos de licitação, de maneira a registrar os valores estimados e contratados. Nos contratos analisados, que estavam em vigência no ano de 2017 , havia contratações firmadas desde 2012. 
Na segunda fase, foram analisados os termos aditivos da prorrogação dos contratos e anotados os valores que foram modificados e feita a comparação com o valor inicialmente contratado, obtendo dessa forma o índice de reajuste.

\section{FUNDAMENTAÇÃO TEÓRICA}

O Estado quando necessita adquirir produtos ou serviços, para a execução das suas atividades, deve estabelecer um processo seletivo, onde todos podem participar e competir em igualdades, conforme estabelece a Constituição Federal.

Esse procedimento administrativo, utilizado pelo Estado para contratar interessados em fornecer bens ou serviços para o atendimento coletivo é denominado Licitação cujas regras são regulamentadas por legislações específicas, de modo a garantir a transparência nas contratações públicas e a isonomia de direitos dos interessados em contratar com o Estado (SOARES JUNIOR, MORAIS, 2016).

\subsection{ADMINISTRAÇÃO PÚBLICA}

O Estado, sob os termos e condições da lei, deve agir para atender as necessidades coletivas e não interesses pessoais ou particulares de um grupo dominante. Nesse sentido, o trabalho de Fonseca, Gusinsky e Bernardes (2014) diz que se convencionou chamar de Administração Pública o aparelhamento criado para apoiar o Estado no seu alcance dos interesses coletivos que não seriam possíveis individualmente.

Não há uniformidade sobre o conceito da Administração Pública, como pode ver, a Constituição Federal dedicou um capítulo inteiro sobre a Administração Pública.

Segundo Pietro (2016), a expressão Administração Pública é distinguida pelos autores, basicamente em dois sentidos: subjetivo e objetivo. No sentido subjetivo, formal ou orgânico, a Administração Pública designa os entes que exercem a atividade administrativa compreendendo pessoas jurídicas, órgãos e agentes públicos. No sentido objetivo, material ou funcional, ela designa a natureza da atividade exercida pelos entes.

Deste modo, a autora conceitua a Administração Pública:

Em sentido objetivo, a Administração Pública abrange as atividades exercidas pelas pessoas jurídicas, órgãos e agentes incumbidos de atender concretamente às necessidades coletivas; corresponde à função administrativa, atribuída preferencialmente aos órgãos do Poder Executivo (PIETRO, 2016). 
Ao conceituar a Administração Pública, no sentido objetivo, Pietro (2016) entende a Administração Pública como a própria função administrativa, predominando o exercício do Poder Executivo na gestão dos interesses públicos, por meio da prestação de serviços públicos.

O estudo crítico realizado por Saraí (2012), sobre o conceito vigente de administração pública, em sua conclusão, apresenta:

Administração pública abrange qualquer sujeito de direito que pratica ato em nome do Estado. Em razão disso, todo ato assim praticado está sujeito aos princípios da legalidade, impessoalidade, moralidade, publicidade e eficiência.

A administração pública não é um conjunto de órgãos e atividades presente dentro e abaixo de cada Poder, é o exercício do poder delegado pelo povo, incluindo o Poder Executivo, o Legislativo e o Judiciário, exercício que deve ser subordinado aos princípios da administração pública.

Desse modo, entende-se que a Administração Pública tem a função de agir em nome do Estado, cumprindo fielmente os comandos normativos para atender os interesses da coletividade e sendo guardiã dos recursos públicos, a sua gestão deve ser pautada nos princípios da legalidade, impessoalidade, da moralidade e da igualdade. E, posteriormente, com a Emenda Constitucional nº 19, de 04 de junho de 1998, foi introduzido o principio da eficiência na Administração Pública.

Meirelles $^{1}$ (2003, apud SOARES E SCARPIM, 2013) vê o principio da eficiência na administração pública como uma ideia de fazer as coisas com racionalidade, medindo os custos em relação ao grau de utilidade alcançado com a satisfação das necessidades públicas.

Para Soares e Scarpim (2013), a definição de eficiência no campo da administração pública gerencial estende-se além do conceito normativo do termo, onde os gestores públicos não tem que se preocupar somente com o cumprimento dos termos legais e correta aplicação dos recursos públicos, mas com a otimização dos gastos públicos em atendimento às demandas coletivas.

Assim, o princípio da eficiência norteia a atividade administrativa no sentido de obter os melhores resultados com os meios escassos de que se dispõe, e a menor custo. Rege-se pela regra do maior benefício com o menor custo possível (SOARES, SCARPIM,2013).

A função da administração pública, na visão dos autores Garcia e Araújo (2012), é realizar ações que apresentem benefícios para a sociedade, dentro do principio da legalidade, garantindo os direitos individuais, ou seja, na Administração Pública, os agentes públicos só podem fazer aquilo que a lei permite. É um princípio, segundo Soares Junior e Morais (2013), que limita o poder dos agenttes da Administração Pública e gera segurança aos cidadãos. 


\subsection{LICITAÇÃO}

A licitação é um procedimento, que a Administração Pública utiliza para adquirir produtos ou serviços necessários para a realização de suas atividades e, como se trata de utilização de recursos públicos, deve seguir critérios estabelecidos pela lei.

Antes da Constituição de 1988, as contratações públicas eram regidas por Decreto ou Lei especifica. A seleção da proposta mais vantajosa para a Administração não seguia os princípios da isonomia e da igualdade perante a lei. Prevalecia o caráter discricionário administrativo, onde o processo de contratação atendia o interesse financeiro do Estado em obter menor preço.

A contratação pública, segundo estudos da ENAP (2014), veio com o Código de Contabilidade Pública da União, organizado pelo Decreto $n^{\circ} 4.536$, de 19 de janeiro de 1922 e posteriormente pela Lei $n^{\circ}$ 4.401/64, mas não focava os princípios da isonomia e da igualdade de todos perante a lei, na seleção da proposta mais vantajosa. Nesta época, o processo de contratação era denominado de concorrência e visava atender ao interesse financeiro do Estado em obter o preço mínimo. De acordo com os estudos da ENAP (2014), o caráter discricionário administrativo do processo de contratação só foi retirado com a Reforma Administrativa Federal, em 1967, por intermédio do Decreto-lei no 200 que transformou o processo de contratação em instituto vinculante e obrigatório, no âmbito da administração federal e mais tarde, através da Lei $\mathrm{n}^{\mathbf{0}}$ 5.456/68 estendeu tal obrigatoriedade para os Estados e Municípios.

As licitações e contratos públicos da administração federal eram regidos pelas regras estabelecidas no Decreto-lei $n^{0}$ 2.300, de 21/11/1986, que também estendeu sua aplicabilidade para os Estados, Municípios e Distrito Federal, porém, somente com a Constituição de 1988 que instituiu os princípios da Administração Pública, foi que a licitação tornou-se obrigatória para toda a Administração Pública (ENAP, 2014).

Na concepção de Oliveira, Almeida e Lopes (2013), a Administração Pública nem sempre dispõe de meios próprios para prover as necessidades da coletividade, no cumprimento da sua missão de gerenciar os serviços públicos, por isso se vê obrigada a adquirir bens, serviços e obras junto à iniciativa privada cujas contratações só podem ser celebradas por processo licitatório, conforme estabelecido no Art. 37 da Constituição Federal de 1988 e que seja assegurada a igualdade de condições entre os concorrentes.

Silva e Carvalho (2017), fundamentado no art. 23 da Lei 8.666/93 ${ }^{4}$,definem licitação como o procedimento administrativo para contratação de serviços ou aquisição de produtos pelo governo, tendo como objetivo a igualdade, transparência e legitimidade e que estas práticas administrativas devem ser orientadas para a busca do interesse público como objetivo final. Os mesmos autores ainda consideram o processo licitatório como sendo um dos principais meios de critério 
da aplicação dos recursos públicos, tendo em vista que, observando as condições de igualdade entre os concorrentes, busca a proposta mais vantajosa para contratação por parte do poder público.

Faria e Oliveira (2016), em suas análises sobre a utilização da licitação pública na modalidade pregão eletrônico, apresentam o vocábulo "licitação" como termo derivado do latim Licitatione cuja finalidade é arrematar em leilão após a formalização de lances. Para os autores, licitação é o procedimento das contratações públicas regulamentado com normas gerais pela Lei $\mathrm{n}^{\mathrm{o}}$ 8.666/93.

Neste sentido, podemos dizer que as propostas apresentadas para as contratações do governo seriam como os lances de um leilão, e o arremate da contratação seria da proposta mais vantajosa, após o atendimento dos critérios, previamente, estabelecidos, como mostra o conceito definido pela ENAP (2014):

É o procedimento administrativo preliminar, mediante o qual a Administração, baseada em critérios prévios, seleciona, entre várias propostas referentes a compras, obras ou serviços, a que melhor atende ao interesse público, a fim de celebrar contrato com o responsável pela proposta mais vantajosa, em observância ao princípio constitucional da isonomia.

No mesmo entendimento de Silva e Carvalho (2017), o conceito de licitação estabelecido pela ENAP (2014) também diz que é um procedimento administrativo, porém acrescenta que é um procedimento prévio, onde a administração contrata os seus fornecedores com base em critérios definidos, observando o princípio constitucional da isonomia.

Outros autores dão maior robustez na conceituação de licitação, estendendo a definição até na capacitação dos proponentes, como na definição dos autores Reitz Júnior e Boselli (2016):

As contratações na Administração Pública são regidas pela Lei no 8.666 , de 21 de junho de 1993 e legislações correlatas, que além de instituírem as modalidades de licitação trazem uma regulamentação apropriada e robusta a fim de garantir a isonomia, assegurando a igualdade entre todos os participantes, selecionando a proposta mais vantajosa para a administração por meio de ampla disputa envolvendo maior número de participantes capacitados a fim de atender o interesse público.

Comparando todos os conceitos, podemos concluir que licitação é o conjunto de procedimentos administrativos para as contratações do governo, nas esferas federal, estadual, distrital e municipal. Neste sentido, no desenvolvimento do presente trabalho, a licitação pública será entendida como uma competição entre os fornecedores interessados nas contratações do governo, por meio de um processo formal e com regras definidas em lei em conformidade com a modalidade da licitação. 
A modalidade indica como irá reger o procedimento da licitação. A Lei 8.666/93 institui como modalidades de licitação o Convite, Tomada de Preços, Concorrência, Leilão, Concurso e a Lei 10.520/2002, que será analisada em outro tópico, criou a modalidade do Pregão. Nestas modalidades, a legislação estabelece qual o tipo de licitação para avaliar e julgar as propostas, quais sejam: menor preço, melhor técnica, técnica e preço e maior lance ou oferta quando se tratar de alienação de bens ou concessão de uso de bens públicos. Na modalidade concurso não se aplicam os tipos de licitação definidos pela lei (FARIA, OLIVEIRA, 2016). O concurso deve ter seus critérios de julgamento estabelecidos de acordo com o seu objeto.

A maior parte das licitações públicas é realizada através da modalidade Pregão, com o uso da tecnologia da Internet, que é uma rede mundial de computadores, Esta modalidade de licitação será tratada no tópico a seguir, com a revisão do seu conceito e de suas normas regulamentadoras.

\subsection{PREGÃO ELETRÔNICO}

A Lei $\mathrm{n}^{\mathbf{0}} 10.520$ foi promulgada em 17 de julho de 2002, e instituiu, no âmbito da Administração Pública, a modalidade de licitação denominada Pregão, simplificando os procedimentos burocráticos, nas contratações públicas de bens e serviços comuns. Isto ocorre porque no Pregão não há limites de valores como nas demais modalidades e a ordem de habilitação e classificação das propostas é invertida, isto é, primeiro toma-se conhecimento do valor ofertado e somente depois que se verificam as condições de habilitação da empresa vencedora para contratar com o Poder Público.

O Pregão Eletrônico, para aquisição de bens e serviços comuns, foi regulamentado pelo Decreto $\mathrm{n}^{\mathrm{o}} 5 \cdot 45 \mathrm{O}$, de 31 de maio de 2005, que no seu Art. $4^{\circ}$, estabeleceu sua obrigatoriedade na Administração Federal e havendo inviabilidade de sua utilização, o dirigente ou a autoridade competente deve apresentar as justificativas, de forma motivada e circunstanciada.

Na modalidade de licitação Pregão, a disputa pelo fornecimento de bens ou serviços à Administração Pública é feita em sessão pública, onde as melhores propostas são classificadas por meio de lances e a vencedora será aquela que ofertar o menor preço. A inovação do pregão está na inversão das fases de habilitação e análise das propostas, onde se verifica a documentação apenas do licitante detentor da melhor proposta.

A legislação que instituiu o Pregão, como modalidade de licitação, não trouxe em seu texto um conceito claro e definidor do Pregão. $\mathrm{O}$ instrumento regulador dessa modalidade de licitação, que foi o Decreto $n^{\mathrm{o}} 5.450$, deveria definir, teoricamente, o que vem a ser uma licitação pública, através da modalidade pregão. Para suprir esta lacuna, Vasconcelos (2005) dá a seguinte definição: 
Como podemos ver, o pregão é a modalidade de licitação para aquisição de bens e serviços comuns em que a disputa pelo fornecimento é feita em sessão pública, por meio de propostas e lances, para classificação e habilitação do licitante com a proposta de menor preço. Sua grande inovação se dá pela inversão das fases de habilitação e análise das propostas, onde se verifica apenas a documentação do participante que tenha apresentado a melhor proposta (VASCONCELOS, 2005).

Enquanto o Tribunal de Contas da União, em suas orientações e jurisprudência, define o Pregão como:

Pregão é modalidade de licitação em que a disputa pelo fornecimento de bens ou serviços comuns é feita em sessão pública, ainda que virtual. Os licitantes após apresentação das propostas com os preços escritos têm a faculdade de reduzi-los mediante lances verbais ou via internet ( TCU, 2010).

No Pregão Eletrônico, o processo é simples e apresenta baixo custo para os competidores por não ser necessário o deslocamento até a sede do órgão promotor da licitação, o que facilita o acesso no mercado de contratações públicas. Neste sentido, segundo os autores Fonseca, Gusinsky, Bernardes (2014), a utilização da Internet para as contratações públicas, na modalidade Pregão Eletrônico, permite maior transparência, amplia o número de participantes, dá maior agilidade no processo e ainda favorece a competição.

Esta lei instituidora da modalidade de licitação Pregão não dispõe de todas as normas para conduzir um processo de licitação. A esse respeito, Fonseca, Gusinsky e Bernardes (2014) apontam que o próprio legislador reconheceu esta lacuna, ao estabelecer no Art. $9^{\circ}$ a aplicação subsidiariamente das normas da Lei 8.666/93 para a modalidade Pregão, ou seja, a Lei 10.520/2002, segundo Faria e Oliveira (2016), contem apenas considerações básicas dos procedimentos do Pregão. Mas os autores Fonseca, Gusinsky e Bernardes (2014) avançam na explicação da duplicidade de aplicação da lei nesta modalidade de licitação, ao afirmarem:

Portanto, para o pregão, em princípio, deve-se obedecer a Lei $n^{\circ}$. 10.520/2002. Em situações em que esta for omissa, recorre-se às normas da Lei no. 8.666/1993. No caso de contradição entre as duas Leis, deve prevalecer a Lei $\mathrm{n}^{\circ}$. 10.520/2002, porque seu conteúdo versa precisamente sobre pregão.

O procedimento licitatório da modalidade Pregão é realizado em duas grandes fases, a interna e externa. Na fase interna, a Administração dá inicio ao processo licitatório, justificando e caracterizando o objeto a ser contratado. É nesta fase que se elabora o Termo de Referência, estabelecendo os critérios para a contratação com o serviço público e 
estimando os custos da contratação e posteriormente definir o instrumento convocatório. Esta fase é também, chamada de preparatória e os detalhes estão definidos no Art. $3^{\underline{0}}$ da Lei 10.520/2002.

A fase externa é onde ocorre a competição para a seleção da proposta mais vantajosa. Seu inicio é caracterizado pela publicação do edital e a disponibilização do instrumento completo aos interessados. Esta fase se encerra com a adjudicação do objeto e homologação do processo licitatório. A sequência dessa fase é detalhada no Art. $4^{\underline{0}}$ da Lei do Pregão.

Na visão de Fonseca, Gusinsky e Bernardes (2014), o Pregão Eletrônico é uma ferramenta dinâmica para processar as aquisições de bens e contratações de serviços na Administração. Para Faria e Oliveira (2016), a inclusão da modalidade Pregão foi um avanço nas licitações públicas e sua forma eletrônica trouxe benefícios da tecnologia para as contratações no âmbito do poder público.

\section{GANHO ECONÔMICO NAS LICITAÇÕES DOS SERVIÇOS TERCEIRIZADOS}

A ordenação dos resultados encontrados, de maneira a alcançar o objetivo proposto, foi com base na coleta de dados dos processos de terceirização da UFPE, cujos contratos estavam em vigência no ano de 2017. As terceirizações da Universidade constituíam em 17 contratos, com 1.065 profissionais prestando atividades nos Campi da UFPE, despendendo para essas contrações o valor próximo de $\mathrm{R} \$ 45$ milhões.

Em consulta nos arquivos da Diretoria de Licitações e Contratos (DLC), unidade vinculada à Pró Reitoria de Gestão Administrativa (PROGEST), foi feita uma análise nos processos de licitação, no período de 2012 a 2017, que deram origem às contratações vigentes, sendo que os dados foram complementados com informações retiradas das atas dos pregões eletrônicos, disponibilizadas no Portal de Compras do Governo Federal, no endereço eletrônico www.comprasnet.gov.br, página da Internet que traz as mais diversas informações a respeito das licitações na esfera pública federal.

Com os dados dessa análise, construiu-se a tabela a seguir: 


\section{Revista}

dos Mestrados

Profissionais

ISSN: 2317-0115

TABELA 1 - Percentual de desconto obtido nos Pregões Eletrônicos para contratação de terceirização na UFPE

\begin{tabular}{|c|c|c|c|c|c|}
\hline PREGÃO & OBJETO & $\begin{array}{l}\text { VALOR } \\
\text { ESTIMADO (R\$) }\end{array}$ & $\begin{array}{c}\text { VALOR } \\
\text { CONTRATADO }(R \$)\end{array}$ & $\begin{array}{l}\text { VALOR DO } \\
\text { DESCONTO (R\$) }\end{array}$ & $\begin{array}{c}\% \\
\text { DESCONTO }\end{array}$ \\
\hline $35 / 2012$ & Serviços de Limpeza e Conservação Predial - Campus Recife & $8.247 .839,32$ & $7.651 .830,34$ & $596.008,98$ & 7,23 \\
\hline $192 / 2012$ & Serviços de Copeiragem & $54.051,80$ & $54.867,60$ & $-815,80$ & * \\
\hline $244 / 2012$ & Serviços de Controle e operação de Elevadores no CFCH & $236.588,76$ & $141.506,04$ & $95.082,72$ & 40,19 \\
\hline $176 / 2013$ & Serviço de Vigilância Armada e Motorizada & $10.295 .984,80$ & $8.099 .958,09$ & $2.196 .026,71$ & 21,33 \\
\hline $237 / 2013$ & $\begin{array}{l}\text { Serviços de Auxiliares na área de Transporte de Passageiros, } \\
\text { Cargas e Mercadorias }\end{array}$ & $2.138 .656,08$ & $1.901 .845,03$ & $236.811,05$ & 11,07 \\
\hline $242 / 2013$ & $\begin{array}{c}\text { Serviços de Limpeza e Conservação de Áreas Externas - } \\
\text { Campus Recife }\end{array}$ & $3.390 .990,52$ & $2.619 .248,88$ & $771.741,64$ & 22,76 \\
\hline $292 / 2013$ & Serviços de Controle, Fiscalização e Operação de Portarias & 2.248.604,48 & $1.918 .992,00$ & $329.612,48$ & 14,66 \\
\hline 96/2014 & $\begin{array}{l}\text { Serviços de Manutenção Predial Preventiva e Corretiva } \\
\text { (Instalações Civis, Hidráulicas e Elétricas) - CAA }\end{array}$ & $1.208 .257,20$ & $999.997,68$ & $208.259,52$ & 17,24 \\
\hline $96 / 2014$ & $\begin{array}{l}\text { Serviços de Manutenção Predial Preventiva e Corretiva } \\
\text { (Instalações Civis, Hidráulicas e Elétricas) - Campus Recife }\end{array}$ & $8.910 .350,64$ & $6.969 .139,68$ & 1.941.210,96 & 21,79 \\
\hline $96 / 2014$ & $\begin{array}{l}\text { Serviços de Manutenção Predial Preventiva e Corretiva } \\
\text { (Instalações Civis, Hidráulicas e Elétricas) - CAV }\end{array}$ & $804.487,44$ & $640.884,84$ & $163.602,60$ & 20,34 \\
\hline $148 / 2014$ & Serviços de Atendimento em Recepção & $230.747,62$ & $195.576,82$ & $35.170,80$ & 15,24 \\
\hline $166 / 2014$ & $\begin{array}{c}\text { Serviços de Controle de Almoxarifado e Apoio à } \\
\text { Administração de Materiais }\end{array}$ & $197.020,32$ & $136.998,12$ & $60.022,20$ & 30,46 \\
\hline $256 / 2014$ & Serviços de Contínuos & $551.366,40$ & $379.000,00$ & $172.366,40$ & 31,26 \\
\hline $241 / 2015$ & Serviço de Atendimento por Telefonista & $209.003,76$ & $184.899,96$ & $24.103,80$ & 11,53 \\
\hline $12 / 2016$ & Serviços de Limpeza e Conservação Predial - CAA & $7.987 .904,19$ & $3.621 .855,80$ & $4.366 .048,39$ & 54,66 \\
\hline $13 / 2016$ & Serviços de Limpeza e Conservação Predial - CAV & $590.589,40$ & $545.646,96$ & $44.942,44$ & 7,61 \\
\hline \multirow[t]{2}{*}{$50 / 2017$} & Serviços de Apoio Operacional & $339.803,28$ & $271.220,40$ & $68.582,88$ & 20,18 \\
\hline & Total & $47.642 .246,01$ & $36.333 .468,24$ & $11.308 .777,77$ & \\
\hline
\end{tabular}

QUADRO 3 - Elaborado pelo autor, com dados coletados na DLC/PROGEST e Site Compras governamentais.

* Não houve desconto, valor foi a maior em 1,51\%. 
Em complemento aos dados elencados na Tabela 1, tem a registrar que a contratação dos Serviços de Controle, Fiscalização e Operação de Portarias, houve rescisão do primeiro contrato firmado, sendo contratada outra empresa remanescente da licitação.

Na pesquisa das atas dos pregões para contratação dos serviços terceirizados da UFPE, foram anotados os valores estimados e os valores contratados e montada a Tabela 1 . Comparando estes valores, o estimado e o contratado, pode-se observar o ganho obtido na seleção da proposta mais vantajosa para a contratação pública, que na tabela está representado pela coluna "desconto". Há de se observar a existência de economia de até $54 \%$ nas contratações pesquisadas. E ainda, a variável "Valor Contratado" apresenta uma média de R \$ 2,137 milhões por contratação e na variável "Valor do Desconto" esta média é de R\$ 665 mil.

Os dados da Tabela 1 mostram que a UFPE, em suas contratações de serviços terceirizados, no período de 2012 a 2017, obteve um desconto na ordem de R $\$ 11,308$ milhões, com percentuais variando de 7 a $54 \%$. E o maior percentual de desconto foi na contratação de serviços de limpeza e conservação predial para o Campus Avançado do Agreste, localizado no interior do estado, na cidade de Caruaru. Foi um percentual na ordem de $54,66 \%$, correspondente ao valor monetário de $\mathrm{R} \$$ 4,366 milhões, quantia que corresponde a 38,60\% do total economizado. Outras contratações também proporcionaram um relevante índice de economia, como as dos serviços de vigilância armada e da manutenção predial (instalações civis, hidráulicas e elétricas - Campus Recife) que apontam, respectivamente, as importâncias de R \$2,196 milhões e R\$ 1,941 milhões.

Na análise dos pregões de terceirização, no período 2012-2017, somente em um pregão a UFPE não conseguiu obter desconto. Foi no Pregão Eletrônico n⿳ำ 192/2012, que teve como objeto a contratação de serviços de copeiragem. Tal serviço foi contratado com um percentual de $1,51 \%$ acima do valor estimado, o que pode ser considerado um valor desprezível, diante da proporção da totalização dos valores economizados.

\section{A EVOLUÇÃO DOS VALORES CONTRATADOS}

Os contratos de terceirização, por ter o seu serviço executado de forma contínua e visando a obtenção de preços e condições vantajosas para a Administração, podem ser prorrogados até o limite de 60 meses (Inciso II, Art. 57, Lei 8.666/93). Desse modo, em via de regra, uma contratação de serviços de terceiros tem vigência de cinco anos. Nesse período, a contratação pode ser ajustada, tanto nos valores da contratação, para manter o equilíbrio econômico e financeiro e atender os interesses da Administração, como também no quantitativo, dentro dos limites estabelecidos pela legislação. 
Os reajustes dos contratos administrativos estão previstos nos termos da Lei n⿳ำ 10.192/2001 e da Lei de Licitações e Contratos, tendo a finalidade de neutralizar os efeitos da inflação e manter o equilíbrio econômico-financeiro, porém só é permitido após decorrer um ano da data da apresentação da proposta.

Ao celebrar o contrato, as partes assumem compromissos, onde o contratado se compromete a realizar os serviços nas condições estabelecidas na sua proposta e a Administração tem a obrigação em pagar o valor acordado, mantendo o equilíbrio econômico-financeiro ao longo do contrato cuja garantia está na Constituição Federal.

Em virtude dessa proteção, quando houver um desequilíbrio, a situação pode ser resolvida por meio de um reajuste ou de uma revisão de preços.

Segundo o site Olicitante (2018), a inflação pode afetar o valor contratado, tornando o seu custo incompatível com a realidade. Esse efeito da desvalorização da moeda pode ser amenizado aplicando os índices previamente estabelecidos no termo contratual ou pela análise da variação dos custos na planilha de preços.

O reajuste do valor contrato, através da análise da variação dos custos que compõem a planilha de preços, é denominado repactuação e somente é possível para serviços contínuos terceirizados com dedicação exclusiva de mão de obra. Para aplicar o reajuste do valor contratado, tanto como a aplicação dos índices econômicos ou a repactuação, deve estar previsto no edital de licitação e, conforme comentado anteriormente, só pode ser concedido após um ano, a contar da data da proposta. Entretanto, a revisão de preços, que é outra forma de manter o equilíbrio econômico-financeiro do contrato, não depende de previsão no edital e pode ser concedida a qualquer tempo, no decorrer do contrato, tendo em vista que o desequilíbrio pode ser provocado por fatores posteriores à contratação, por exemplo, a criação de um novo imposto que venha onerar os custos do contratado (OLICITANTE, 2018).

A manutenção do equilíbrio econômico-financeiro do contrato não protege apenas o particular que presta serviços à Administração Pública. Também é um direito da Administração que poderá pagar um valor menor do que foi contratado, quando houver, comprovadamente, a redução dos custos da empresa contratada. Neste sentido, já houve entendimento do Tribunal de Contas da União (TCU), que no Acórdão 2.859/2013 - Plenário, amparado no Art. 65, § 5으, da Lei no 8.666/93, reconheceu que a desoneração da folha de pagamento reduzia os custos dos contratos firmados com a Administração e, por isso, recomendou a revisão dos valores dos contratos firmados (COMPRASGOVERNAMENTAIS, 2014). 
TABELA 2 - Contratos de Terceirização da UFPE - Comparação Valor contratado com o valor vigente no ano 2017

\begin{tabular}{|c|c|c|c|c|c|}
\hline OBJETO & $\begin{array}{c}\text { VALOR } \\
\text { CONTRATADO } \\
(R \$)\end{array}$ & $\begin{array}{l}\text { VALOR EM } \\
2017(\mathrm{R} \$)\end{array}$ & $\begin{array}{l}\text { VARIAÇÃO } \\
\quad \% \cong\end{array}$ & $\begin{array}{l}\text { CONTRATO } \\
\mathrm{N}^{\circ}\end{array}$ & $\begin{array}{l}\text { INÍCIO DA } \\
\text { VIGÊNCIA }\end{array}$ \\
\hline $\begin{array}{l}\text { Serviços de Limpeza e } \\
\text { Conservação Predial - } \\
\text { Campus Recife }\end{array}$ & $7.651 .830,34$ & $9.061 .764,84$ & 18 & $88 / 2012$ & 04.12 .2012 \\
\hline Serviços de Copeiragem & $54.867,60$ & $67.689,72$ & 23 & $04 / 2013$ & 08.01 .2013 \\
\hline $\begin{array}{c}\text { Serviços de Controle e } \\
\text { Operação de Elevadores } \\
\text { no CFCH }\end{array}$ & $141.506,04$ & $196.407,48$ & 39 & $108 / 2013$ & 09.09 .2013 \\
\hline $\begin{array}{l}\text { Serviço de Vigilância } \\
\text { Armada e Motorizada }\end{array}$ & $8.099 .958,09$ & $\begin{array}{c}13.772 .035,78 \\
W\end{array}$ & 70 & $37 / 2014$ & 11.04 .2014 \\
\hline $\begin{array}{c}\text { Serviços de Auxiliares na área } \\
\text { de Transporte de Passageiros, } \\
\text { Cargas e Mercadorias }\end{array}$ & $1.901 .845,03$ & $2.255 .394,48$ & 19 & $30 / 2014$ & 17.03.2014 \\
\hline $\begin{array}{l}\text { Serviços de Limpeza e } \\
\text { Conservação de Áreas } \\
\text { Externas - Campus Recife }\end{array}$ & $2.619 .248,88$ & $2.481 .280,80$ & -5 & $10 / 20014$ & 29.01.2014 \\
\hline $\begin{array}{c}\text { Serviços de Manutenção } \\
\text { Predial Preventiva e } \\
\text { Corretiva (Instalações Civis, } \\
\text { Hidráulicas e Elétricas) - } \\
\text { CAA }\end{array}$ & $999.997,68$ & $1.189 .251,84$ & 19 & $95 / 2014$ & 01.09 .2014 \\
\hline $\begin{array}{l}\text { Serviços de Manutenção } \\
\text { Predial Preventiva e } \\
\text { Corretiva (Instalações Civis, } \\
\text { Hidráulicas e Elétricas) - } \\
\text { Campus Recife }\end{array}$ & $6.969 .139,68$ & $6.821 .929,56$ & -2 & $88 / 2014$ & 01.09 .2014 \\
\hline $\begin{array}{c}\text { Serviços de Manutenção } \\
\text { Predial Preventiva e } \\
\text { Corretiva (Instalações Civis, } \\
\text { Hidráulicas e Elétricas) - CAV }\end{array}$ & $640.884,84$ & $671.769,48$ & 5 & $123 / 2014$ & 06.11 .2014 \\
\hline $\begin{array}{l}\text { Serviços de Atendimento } \\
\text { em Recepção }\end{array}$ & $195.576,82$ & $195.576,82$ & 0 & $135 / 2014$ & 16.03 .2015 \\
\hline $\begin{array}{l}\text { Serviços de Controle de } \\
\text { Almoxarifado e Apoio à } \\
\text { Administração de Materiais }\end{array}$ & $136.998,12$ & $135.107,52$ & -1 & $35 / 2015$ & 11.05 .2015 \\
\hline Serviços de Contínuos & $379.000,00$ & $411.991,92$ & 9 & $68 / 2015$ & 03.08.2015 \\
\hline $\begin{array}{l}\text { Serviço de Atendimento } \\
\text { por Telefonista }\end{array}$ & $184.899,96$ & $201.920,61$ & 9 & $36 / 2016$ & 29.06 .2016 \\
\hline $\begin{array}{c}\text { Serviços de Limpeza e } \\
\text { Conservação Predial - CAA }\end{array}$ & $3.621 .855,80$ & $3.858 .033,60$ & 7 & $59 / 2016$ & 29.08 .2016 \\
\hline $\begin{array}{c}\text { Serviços de Limpeza e } \\
\text { Conservação Predial - CAV }\end{array}$ & $545.646,96$ & $563.124,71$ & 3 & $60 / 2016$ & 29.08 .2016 \\
\hline $\begin{array}{l}\text { Serviços de Apoio } \\
\text { Operacional }\end{array}$ & $271.220,40$ & $271.220,40$ & - & $50 / 2017$ & 03.05.2017 \\
\hline $\begin{array}{l}\text { Serviços de Controle, } \\
\text { Fiscalização e Operação } \\
\text { de Portarias }\end{array}$ & 2.627.712,00 & $2.627 .712,00$ & - & $65 / 2017^{*}$ & 20.06 .2017 \\
\hline Total & $37.042 .188,24$ & $44.782 .211,56$ & 21 & & \\
\hline
\end{tabular}

FONTE: Elaborado pelo autor, com dados coletados na DLC/PROGEST e site

COMPRASGOVERNAMENTAIS.

${ }^{*}$ Remanescente da licitação - substituição de contrato rescindido 
Tomando como base os contratos de terceirização, firmados pela UFPE, e em vigência no ano 2017, elaborou-se a Tabela 2 e comparou o valor contratado, quando se concluiu o processo de licitação, com o valor atualizado em 2017. A soma dos valores contratados envolvia 37,042 milhões de reais e com os reajustes passaram a ter o valor de 44,782 milhões de reais, representando um acréscimo nos custos dos serviços terceirizados em torno de $21 \%$.

A Tabela 2 mostra os contratos da UFPE, vigente em 2017, com seus reajustes. A variação desses reajustes, comparado com o valor original da contratação, apresenta índice de apenas um dígito e, em certos contratos, esse índice foi negativo em razão da publicação do Decreto $n^{0}$ 8.540, de 9 de outubro de 2015, onde foi estabelecido, no âmbito da Administração Pública Federal, medidas de racionalização dos gastos públicos nas contratações para aquisições de bens e prestação de serviços.

Assim, a média da modificação dos valores contratos foi de $12 \%$, tendo uma mediana de $6,5 \%$ e limite mínimo em $-5 \%$ com o máximo em $70 \%$.

Em atendimento a esse Decreto, a Universidade Federal de Pernambuco avaliou seus contratos de serviços terceirizados e em concordância com as empresas prestadoras de serviços refez seu projeto, promovendo alterações para racionalizar suas despesas.

A Tabela 2, que compara o valor contratado com o valor vigente, no ano 2017, apresenta dados de duas contratações com alto índice de reajuste. Uma é a contratação de Serviços de Controle e Operação de Elevadores no $\mathrm{CFCH}$ - Centro de Filosofia e Ciências Humanas, que teve uma variação de $39 \%$ e a outra é a de Serviço de Vigilância Armada e Motorizada, com variação de $70 \%$ no reajuste. Estas duas contratações são um caso à parte cuja explicação, para tais números, consiste no acréscimo dos serviços contratados. Nos serviços de vigilância, o quantitativo do serviço contrato foi acrescido, aplicando todo o limite legal, e ainda as repactuações previstas para garantir o equilíbrio econômico-financeiro do contrato, o que justifica o contrato estar $70 \%$ do valor inicial. Na contratação dos serviços de controle e operação dos elevadores, além de haver as repactuações, legalmente previstas, o serviço foi acrescido com a entrada em operação de novos elevadores adquiridos pela UFPE.

A seguir, são apresentadas tabelas, comparando o Índice de Preços ao Consumidor Amplo - IPCA acumulado com o índice de reajuste do contrato, a partir do valor original. Estas tabelas foram construídas com dados da pesquisa realizada nos termos aditivos de contratos selecionados, tendo como referência valores relevantes e tempo em vigência. Quanto ao índice do IPCA acumulado, na data de reajuste do contrato, a obtenção dos dados foi através do uso da ferramenta "calculadora do cidadão", disponível no site do Banco Central. 
tabela 3 - Serviços de Limpeza e Conservação Predial - Campus Recife. Contrato nº 88/2012 Início 04/12/2012 - Valor contratado: 7.651.830,34

\begin{tabular}{c|c|c|c|c} 
REAJUSTES & DATA & $\begin{array}{c}\text { VALOR } \\
(\mathrm{R} \$)\end{array}$ & $\begin{array}{c}\% \cong \text { DO VALOR } \\
\text { CONTRATADO }\end{array}$ & $\begin{array}{c}\text { IPCA ACUMULADO } \\
\text { (INICIO CONTRATO- } \\
\text { DATA REAJUSTE) \% } \cong\end{array}$ \\
\hline $1^{\circ}$ & $04 / 07 / 2013$ & $8.097 .025,74$ & 6 & 3,96 \\
\hline $2^{\underline{o}}$ & $03 / 12 / 2013$ & $8.133 .606,36$ & 6 & 5,77 \\
\hline $3^{\circ}$ & $28 / 03 / 2014$ & $8.538 .491,96$ & 12 & 8,07 \\
\hline $4^{\circ}$ & $03 / 12 / 2014$ & $8.731 .294,56$ & 14 & 12,70 \\
\hline $5^{\circ}$ & $11 / 06 / 2015$ & $8.801 .525,70$ & 15 & 19,65 \\
\hline $6^{\circ}$ & $03 / 12 / 2015$ & $8.639 .016,36$ & 13 & 24,51 \\
\hline $7^{\circ}$ & $10 / 03 / 2016$ & $9.049 .875,12$ & 18 & 28,45 \\
\hline $8^{\circ}$ & $29 / 11 / 2016$ & $8.395 .737,14$ & 10 & 32,97 \\
\hline $9^{\circ}$ & $01 / 12 / 2016$ & $8.080 .395,72$ & 6 & 33,21 \\
\hline $10^{\circ}$ & $09 / 05 / 2017$ & $8.235 .983,68$ & 8 & 35,09 \\
\hline $11^{\circ}$ & $19 / 07 / 2017$ & $9.061 .764,84$ & 18 & 35,19 \\
\hline
\end{tabular}

FONTE: Elaborado pelo autor com dados da DLC/PROGEST e uso da ferramenta "calculadora do cidadão", disponível no site do Banco Central.

A Tabela 3 mostra que o contrato de Serviços de Limpeza e Conservação Predial - Campus Recife teve uma significante redução no seu valor, no ano 2016. A redução do valor contratual foi resultado da avaliação desse contrato, feita pela universidade, para atender as medidas de racionalização, estabelecidas pelo Poder Executivo, através do Decreto no 8.540/2015.

TAbela 4 - Serviço de Vigilância Armada e Motorizada Contrato n⿳⺈ 37/2014 Inicio11/04/2014 - Valor contratado: 8.099.958,09

\begin{tabular}{|c|c|c|c|c|}
\hline REAJUSTES & DATA & $\begin{array}{l}\text { VALOR } \\
\text { (R\$) }\end{array}$ & $\begin{array}{l}\% \cong \text { DO VALOR } \\
\text { CONTRATADO }\end{array}$ & $\begin{array}{l}\text { IPCA ACUMULADO } \\
\text { (INICIO CONTRATO- } \\
\text { DATA REAJUSTE) \% }\end{array}$ \\
\hline $1^{\mathrm{o}}$ & $10 / 09 / 2014$ & $9.269 .457,85$ & 14 & 1,80 \\
\hline $2^{\mathrm{o}}$ & $24 / 11 / 2014$ & $9.828 .110,00$ & 21 & 2,81 \\
\hline $3^{0}$ & 09/04/2015 & $10.716 .155,28$ & 32 & 8,12 \\
\hline $4^{\mathrm{o}}$ & $11 / 11 / 2015$ & $11.632 .683,72$ & 44 & 13,02 \\
\hline $5^{\mathrm{o}}$ & $24 / 11 / 2016$ & $12.952 .304,08$ & 60 & 21,91 \\
\hline $6^{-}$ & $10 / 04 / 2017$ & $12.922 .634,69$ & 60 & 23,68 \\
\hline $7^{0}$ & 06/11/2017 & $13.772 .035,78$ & 70 & 25,21 \\
\hline
\end{tabular}

FONTE: Elaborado pelo autor com dados da DLC/PROGEST e uso da ferramenta "calculadora do cidadão", disponível no site do Banco Central.

Os dados da Tabela 4 registram que o contrato de serviços de vigilância armada, ao longo da sua execução, teve reajustes com índices adversos dos demais contratos. Com três anos e sete meses de vigência, o valor do contrato foi reajustado em $70 \%$. Como se trata de um serviço essencial e de relevante interesse da administração, em razão do objeto contratual constituir em manter a segurança das instalações físicas da UFPE, preservando o patrimônio, e ainda garantir a segurança da comunidade universitária, não foi objeto de estudo para atender as medidas de racionalização estabelecidas pelo Decreto Federal nº 8.540/2015. 
Observando esses reajustes, nota-se que esta contratação, inicialmente, não atendeu o planejamento das necessidades demandadas pela Instituição e nem que tenha sido prejudicada pela morosidade do processo licitatório.

Por outro lado, há existência de contratações com reduções dos valores de seus serviços. As Tabelas 5 e 6 apresentam esses contratos com índices significativos de redução nos valores dos contratos, indicando racionalização das despesas públicas.

TABela 5 - Serviços de Limpeza e Conservação de Áreas Externas - Campus Recife Contrato $\mathrm{n}^{\mathrm{O}}$ 10/20014 inicio 29/01/2014 - Valor contratado: 2.619.248,88

\begin{tabular}{c|c|c|c|c} 
REAJUSTES & DATA & $\begin{array}{c}\text { VALOR } \\
(\mathrm{R} \$)\end{array}$ & $\begin{array}{c}\% \cong \text { DO VALOR } \\
\text { CONTRATADO }\end{array}$ & $\begin{array}{c}\text { IPCA ACUMULADO } \\
\text { (INICIO CONTRATO- } \\
\text { DATA REAJUSTE) \% } \cong\end{array}$ \\
\hline $1^{\mathrm{o}}$ & $28 / 01 / 2015$ & $2.743 .312,92$ & 5 & 6,40 \\
\hline $2^{\underline{o}}$ & $28 / 01 / 2016$ & $2.730 .352,92$ & 4 & 17,76 \\
\hline $3^{\underline{o}}$ & $19 / 01 / 2017$ & $2.392 .028,36$ & -9 & 25,17 \\
\hline $4^{\underline{o}}$ & $26 / 01 / 2017$ & $2.546 .857,55$ & -3 & 25,17 \\
\hline $5^{\underline{o}}$ & $27 / 01 / 2017$ & $2.481 .280,80$ & -5 & 25,17
\end{tabular}

FONTE: elaborado pelo autor com dados da DLC/PROGEST e uso da ferramenta "calculadora do cidadão", disponível no site do Banco Central.

A variação negativa do reajuste, mostrada nas Tabelas 5 e 6, se justifica por dois motivos. Primeiro foi a ocorrência da desoneração de insumos/equipamentos, cujos custos deixaram de fazer parte da planilha de preços, na prorrogação da vigência do contrato, por terem sido amortizados no primeiro ano da contratação ${ }^{5}$ e o outro motivo foi em atendimento das medidas de racionalização das despesas públicas da União, estabelecidas pelo Decreto no 8.540 de og de outubro de 2015.

TABela 6 - Serviços de Manutenção Predial Preventiva e Corretiva (Instalações Civis, Hidráulicas e Elétricas) - Campus Recife

Contrato no 88/2014 Inicio 01/09/2014 - Valor contratado: 6.969.139,68

\begin{tabular}{c|c|c|c|c} 
REAJUSTES & DATA & $\begin{array}{c}\text { VALOR } \\
(\mathrm{R} \$)\end{array}$ & $\begin{array}{c}\% \cong \text { DO VALOR } \\
\text { CONTRATADO }\end{array}$ & $\begin{array}{c}\text { IPCA ACUMULADO } \\
\text { (INICIO CONTRATO- } \\
\text { DATA REAJUSTE) \% } \cong\end{array}$ \\
\hline $1^{\circ}$ & $31 / 08 / 2015$ & $7.359 .144,12$ & 6 & 9,28 \\
\hline $2^{\circ}$ & $01 / 06 / 2016$ & $6.968 .904,83$ & 0 & 17,80 \\
\hline $3^{\circ}$ & $31 / 08 / 2016$ & $6.062 .992,20$ & -13 & 18,83 \\
\hline $4^{\circ}$ & $11 / 10 / 2016$ & $6.087 .734,88$ & -13 & 19,45 \\
\hline $5^{\circ}$ & $23 / 05 / 2017$ & $6.821 .929,56$ & -2 & 21,66 \\
\hline
\end{tabular}

FONTE: Elaborado pelo autor com dados da DLC/PROGEST e uso da ferramenta "calculadora do cidadão", disponível no site do Banco Central. 


\subsection{OS REAJUSTES DOS CONTRATOS TERCEIRIZADOS E O ÍNDICE INFLACIONÁRIO}

Visando apresentar a evolução dos reajustes dos contratos, através das repactuações homologadas, foi construída a Tabela 7 com dados coletados nas pesquisas realizadas nos termos aditivos das contratações terceirizadas. Os registros da coluna Índice de Reajuste foram obtidos através da divisão do valor contratado pelo valor vigente em 2017. Quanto ao IPCA acumulado no período, os dados foram obtidos através da ferramenta "calculadora do cidadão", disponível no site do Banco Central.

TABELA 7 - Evolução dos Valores dos Contratos Terceirizados: Índice de Reajuste $x$ IPCA Acumulado - Período 2012 a 2017

\begin{tabular}{|c|c|c|c|}
\hline ОвJето & $\begin{array}{l}\text { VALOR } \\
\text { VIGENTE EM } \\
2017 \\
(\mathrm{R} \$)\end{array}$ & $\begin{array}{c}\text { ÍNDICE } \\
\text { REAJUSTE \% } \\
\text { (SOBRE O VALOR } \\
\text { CONTRATADO) }\end{array}$ & $\begin{array}{c}\text { IPCA } \\
\text { ACUMULADO } \\
\text { NO PERÍODO } \\
\text { DA VIGÊNCIA } \\
\text { DO CONTRATO }\end{array}$ \\
\hline $\begin{array}{c}\text { Serviços de Limpeza e } \\
\text { Conservação Predial - Campus } \\
\text { Recife } \\
\end{array}$ & $9.061 .764,84$ & 18 & 35,19 \\
\hline Serviços de Copeiragem & $67.689,72$ & 23 & 35,49 \\
\hline $\begin{array}{l}\text { Serviços de Controle e operação } \\
\text { de Elevadores no CFCH }\end{array}$ & $196.407,48$ & 39 & 30,25 \\
\hline $\begin{array}{c}\text { Serviço de Vigilância Armada e } \\
\text { Motorizada }\end{array}$ & $13.772 .035,78$ & 70 & 25,21 \\
\hline $\begin{array}{c}\text { Serviços de Auxiliares na área de } \\
\text { Transporte de Passageiros, Cargas } \\
\text { e Mercadorias }\end{array}$ & $2.255 .394,48$ & 19 & 25,38 \\
\hline $\begin{array}{c}\text { Serviços de Limpeza e } \\
\text { Conservação de Áreas Externas - } \\
\text { Campus Recife }\end{array}$ & $2.481 .280,80$ & -5 & 25,17 \\
\hline $\begin{array}{c}\text { Serviços de Manutenção } \\
\text { Predial Preventiva e Corretiva } \\
\text { (Instalações Civis, Hidráulicas e } \\
\text { Elétricas) - CAA }\end{array}$ & $1.189 .251,84$ & 19 & 22,28 \\
\hline $\begin{array}{c}\text { Serviços de Manutenção } \\
\text { Predial Preventiva e Corretiva } \\
\text { (Instalações Civis, Hidráulicas e } \\
\text { Elétricas) - Campus Recife }\end{array}$ & $6.821 .929,56$ & -2 & 21,66 \\
\hline $\begin{array}{c}\text { Serviços de Manutenção } \\
\text { Predial Preventiva e Corretiva } \\
\text { (Instalações Civis, Hidráulicas e } \\
\text { Elétricas) - CAV } \\
\end{array}$ & $671.769,48$ & 5 & 17,66 \\
\hline $\begin{array}{l}\text { Serviços de Atendimento em } \\
\text { Recepção }\end{array}$ & $195.576,82$ & 0 & 15,60 \\
\hline $\begin{array}{c}\text { Serviços de Controle de } \\
\text { Almoxarifado e Apoio à } \\
\text { Administração de Materiais }\end{array}$ & $135.107,52$ & -1 & 9,27 \\
\hline Serviços de Contínuos & $411.991,92$ & 9 & 11,67 \\
\hline $\begin{array}{c}\text { Serviço de Atendimento por } \\
\text { Telefonista }\end{array}$ & 201.920,61 & 9 & 3,59 \\
\hline
\end{tabular}




\begin{tabular}{c|c|c|c}
\hline $\begin{array}{c}\text { Serviços de Limpeza e } \\
\text { Conservação Predial - CAA }\end{array}$ & $3.858 .033,60$ & 7 & 2,46 \\
\hline $\begin{array}{c}\text { Serviços de Limpeza e } \\
\text { Conservação Predial - CAV }\end{array}$ & $563.124,71$ & 3 & 2,71 \\
\hline Serviços de Apoio Operacional & $271.220,40$ & - & - \\
\hline $\begin{array}{c}\text { Serviços de Controle, Fiscalização } \\
\text { e Operação de Portarias }\end{array}$ & $2.627 .712,00$ & - & - \\
\hline
\end{tabular}

FONTE: Elaborado pelo autor com dados da DLC/PROGEST e uso da ferramenta "calculadora do cidadão", disponível no site do Banco Central.

A Tabela 7 apresenta duas contratações sem o índice de reajuste e IPCA acumulado, pelo fato de serem contratações que foram realizadas no ano de 2017. Nesta Tabela, algumas contratações apresentaram índice negativo de reajuste, em decorrência do atendimento das medidas de racionalização das despesas públicas, estabelecidas pela União, através de decreto presidencial no 8.540/2015.

Os registros da Tabela 7 indicam que os reajustes das contratações terceirizadas, ora analisadas, não acompanham os índices do IPCA, que é o indicador oficial da inflação do país. A tabela foi elaborada para ter um parâmetro nos reajustes contratuais; saber se a majoração dos valores contratados é compatível com o índice inflacionário, no período estudado.

A Tabela 7 mostra que os reajustes dos contratos, comparados com o IPCA, acumulado no período, ficam abaixo da inflação, ao longo da sua vigência. A exceção foi nos contratos dos serviços de controle e operação de elevadores e serviço de vigilância armada, em razão do acréscimo de serviços nessas contrações, por necessidades da Administração.

\section{SÍNTESE DOS RESULTADOS}

A análise das contratações terceirizadas da UFPE, vigente no ano 2017 , tem como resultado que estas contratações foram estimadas em $R \$ 47,642$ milhões e os valores, efetivamente contratados, somaram a quantia de $\mathrm{R} \$ 36,333$ milhões, proporcionando uma economia de $23,7 \%$, ou seja, a UFPE economizou R $\$ 11,308$ milhões no pagamento da despesa de serviços prestados por pessoa jurídica. Na maioria dessas contratações ( $41 \%)$, o índice de economia foi na faixa de $15 \%$ a $30 \%$, comparando valor estimado com o valor contratado.

As contratações terceirizadas, ao longo da sua execução, têm os seus custos reajustados, em função da variação dos insumos e dos dissídios coletivos das categorias profissionais. Mas, esses reajustes dos valores contratados não afetam a economia obtida no pagamento dessas despesas, tendo em vista que o índice do reajuste apresenta variação abaixo da inflação medida pelo IPCA. E, em alguns contratos, esse índice foi negativo, em razão da racionalização das despesas públicas, determinadas pelo decreto governamental, no ano de 2015. 


\section{CONSIDERAÇÕES FINAIS}

Diante do que foi discutido no desenvolvimento desta pesquisa, através dos dados obtidos por meio da análise dos processos de contratação de serviços terceirizados da UFPE, da consulta ao site de compras do Governo Federal e da pesquisa bibliográfica, foi possível alcançar o objetivo proposto.

Este trabalho teve como objetivo geral apresentar a economicidade na contratação de serviços terceirizados, com dedicação exclusiva de mão de obra, e analisar os reajustes desses contratos, ao longo da sua execução, tendo como referência os contratos vigentes no ano de 2017.

Após análise dos dados coletados, percebeu-se, que a UFPE, no período de 2012 a 2017, obteve uma economia de R \$11,308 milhões, o que representa, aproximadamente, $24 \%$ do total do valor que foi estimado para a licitação das contratações de terceirizados. Outro fato relevante é que cerca de $53 \%$ dessas contratações apresentaram índice de economia acima dos $20 \%$, destacando a contratação de serviços de limpeza e conservação predial do campus avançado, em Caruaru, onde a UFPE obteve uma economia próxima de $55 \%$, algo em torno de 4,3 milhões de reais, ou seja, valor que corresponde a despesa de 14 meses do contrato firmado com a empresa vencedora da licitação.

Quanto aos reajustes dos contratos, ao longo da sua vigência, a pesquisa mostrou que a majoração dos valores contratados é realizada por meio de repactuações, onde as contratadas demonstram, através de planilhas de custos, a variação dos custos para realizar o serviço para o qual foram contratadas, cabendo à Administração verificar a conformidade dessas planilhas, analisando os efeitos provocados nos salários dos funcionários terceirizados, por força de acordos ou convenções coletivas celebrados, na ocasião da data-base das categorias profissionais vinculadas ao contrato, e ratificar o reajuste pretendido. Essas repactuações não acompanham o índice inflacionário medido pelo IPCA, e suas variações, em termos percentuais, são abaixo da inflação, exceto nos primeiros anos da vigência do contrato, devido à não atualização da proposta apresentada no processo de licitação.

A pesquisa limitou-se em analisar a economicidade das contratações de serviços terceirizados, procedendo estudos comparativos sobre o valor estimado e o valor contratado, como também foi analisada a evolução da majoração dos valores contratados ao longo da execução dos serviços. Os resultados apresentam dados relevantes que merecem uma análise mais profunda, por isso fica a recomendação para futuras pesquisas que possam analisar esses dados, com maior abrangência, e assim complementarem esse estudo.

No presente estudo, foram comparados os valores estimados no termo de referência para o processo seletivo de empresas prestadoras de serviços, com os valores efetivamente contratados e ainda os valores repactuados ao longo da execução do contrato, com o índice oficial 
medidor da inflação no país, tendo o resultado dessas confrontações apresentado significante economia para a UFPE. Assim, pode considerar uma veracidade a afirmação que as contratações de serviços terceirizadas praticadas pela Universidade Federal de Pernambuco proporcionam economia para a Administração Pública.

\section{REFERÊNCIAS}

BANCO CENTRAL DO BRASIL, site Institucional. Calculadora do Cidadão. Disponível em https://www.bcb.gov.br/ calculadora/calculadoracidadao.asp. Acesso em 16 abr 2018.

BRASIL. Decreto nํ⒌450, de 31 de maio de 2005. Regulamenta o Pregão, na Forma Eletrônica, para Aquisição de Bens e Serviços Comuns, e Dá Outras Providências. Lex. Brasília, DF.

Decreto $n^{0}$ 8.540, de o9 de outubro de 2015 .

Estabelece, no âmbito da administração pública federal direta, autárquica e fundacional, medidas de racionalização do gasto público nas contratações para aquisição de bens e prestação de serviços e na utilização de telefones celulares corporativos e outros dispositivos. Lex. Brasília.

. Lei no 8.666, de 21 de junho de 1993.

Regulamenta o art. 37, inciso XXI, da Constituição Federal, institui normas para licitações e contratos da Administração Pública e dá outras providências. Lex.

.Lei $\mathrm{n}^{\mathrm{o}} 10.192$, de 14 de fevereiro de 2001. Dispõe sobre medidas complementares ao Plano Real e dá outras providências. Lex.

. Lei $\mathrm{n}^{\mathrm{o}}$ 10.520, de 17 de julho de 2002. Institui, no âmbito da União, Estados, Distrito Federal e Municípios, nos termos do art. 37, inciso XXI, da Constituição Federal, modalidade de licitação denominada pregão, para aquisição de bens e serviços comuns, e dá outras providências. Lex. Brasília.

. Portal de Compras, site Institucional. Disponível em https://www.comprasgovernamentais.gov.br/index. php/consultass\#accordion. Acesso em 20 abr 2018.

Portal de Compras, site Institucional.

Disponível em http://www.comprasnet.gov.br/noticias/ noticias1.asp?id_noticia=697. Acesso em 28 abr 2018. 


\section{ENAP, Fundação Escola Nacional de Administração}

Pública. Legislação Aplicada à Logística de Suprimentos Lei no 8.666/93, pregão e registro de preços, Módulo 1 A Importância e Necessidade da Lei de Licitações, Brasília, 2014. Disponível em $<\mathrm{http}$ ://repositorio.enap. gov.br/handle/1/858>. Acesso em 10 out 2017 .

FARIA, Messias Anain Almeida; OLIVEIRA, Ionara Lúcia de Melo Castro. Licitação Pública: Análise da Utilização da Modalidade Pregão Na Forma Eletrônica - Pregão Eletrônico. Revista Eletrônica de Educação da Faculdade Araguaia, Goiânia, v. 9, p.349 -366, jun. 2016. Semestral. Disponível em: <http://www.faculdadearaguaia.edu. br/sipe/index. php/renefara/issue/view/33>. Acesso em 04 out. 2017.

FONSECA, Novânia Nunes; GUSINSKY, Matheus Nunes; BERNARDES, José Francisco. Vantagens do Pregão Eletrônico no Setor Público. In: XIV COLÓQUIO INTERNACIONAL DE GESTÃO UNIVERSITÁRIA - CIGU, 14., 2014, Florianópolis Sc. Anais... . Florianopolis - Sc: A Gest Ão do Conhecimento e Os Novos Modelos de Universidade, 2014. p. 1 - 17. Disponível em: $<$ http://www.repositorio.ufsc.br. $>$. Acesso em: 15 out. 2017.

GARCIA, Rayssa Cardoso; ARAÚJO, Jailton Macena de. Os princípios da administração pública no sistema jurídico brasileiro. In: Âmbito Jurídico, Rio Grande, XV, n. 96, jan 2012. Disponível em: <http://www.ambito-juridico.com. br/site/index.php?n_link=revista_artigos_leitura\&artigo_ $\mathrm{id}=11022 \&$ revista_caderno=4>. Acesso em 24 abr 2018.

GIL, Antonio Carlos. Como Elaborar Projetos de Pesquisa. 4. ed. São Paulo: Atlas, 2002.

IBGE, site Institucional. Índice Nacional de Preços ao Consumidor Amplo - IPCA. O qu é. Disponível em https:// www.ibge.gov.br/estatisticas-novoportal/economicas/precose-custos/9256-indice-nacional-de-precos-ao-consumidoramplo.html?=\&t=o-que-e. Acesso em 26 abr 2018

MINISTÉRIO DO PLANEJAMENTO ORÇAMENTO E GESTÃO. Instrução Normativa $n^{\circ}$ 02, de 30 de abril de 2008. Dispõe sobre regras e diretrizes para a contratação de serviços, continuados ou não. In. Brasília, DF, Instrução Normativa n⿳0 05, de 27 de junho de 2014. Dispõe sobre os procedimentos administrativos básicos para a realização de pesquisa de preços para a aquisição de bens e contratação de serviços em geral. In. Brasília, DF, 
2017. Dispõe sobre as regras e diretrizes do procedimento de contratação de serviços sob o regime de execução indireta no âmbito da Administração Pública federal direta, autárquica e fundacional. In. Brasília, DF,

OLICITANTE. Reajuste, repactuação e revisão: mecanismos de recomposição do equilíbrio econômicofinanceiro do contrato. Disponível em http://www. olicitante.com.br/reajuste-repactuacao-revisaocontrato-administrativo/ . Acesso em 25 abr 2018.

OLIVEIRA, Ari Eduardo de; ALMEIDA, Damiana Machado de; LOPES, Luis Felipe Dias. Processo Licitatório de Bens, Obras e Serviços do Poder Público e Seus Princípios Norteadores. Revista Pensamento \& Realidade, São Paulo -sp, v. 28, n. 1, p.144-164, abr. 2013.

Quadrimestral. Disponível em: <https://revistas. pucsp.br/index. php/pensamentorealidade/issue/ view/1074>. Acesso em: 14 out. 2017.

PIETRO, Maria Sylvia Zanella di. Direito Administrativo. 29. ed. Rio de Janeiro: Forense, 2016

REITZ JÚNIOR, Nilson; BOSELLI, Felipe. Planejamento Administrativo para Contratação de Bens e Serviços Usuais na Administração Pública. Revista Empreendorismo e Sustentabilidade - 2016, São José - Sc, v. 1, n. 1, p.45-63, dez. 2016. Anual. Disponível em: <http://www.icepsc.com.br/ojs/ index. php/empreendedorismo/index $>$. Acesso em: o8 out. 2017.

SARAI, Leandro. Repensando o Conceito de Administração Pública na Busca da Máxima Efetividade de seus Princípios Constitucionais. Revista Virtual da Agu, [s.1], v. o, n. 119, p.1-15, o3 jan. 2012. Mensal. Disponível em: <http://186.231.10.13/page/ content/detail/id_conteudo/172274>. Acesso em: 29 out. 2017.

SILVA, Maria de Fátima N. da; CARVALHO, Maria Balbina de. A Gestão de Compras e o Processo de Licitação no Setro Público. Cadernos de Graduação: Ciências Humanas e Sociais, Aracaju, v. 4, n. 1, p.165-178, mar. 2017. Disponível em: <https://periodicos. set.edu.br/index.php/cadernohumanas $>$. Acesso em: 04 out. 2017.

SOARES JUNIOR, Francisco Valmir Dias; MORAIS, Hugo Azevedo Rangel de. PREGÃO ELETRÔNICO: um estudo da economicidade propiciada ao Instituto Federal de Educação, Ciência e Tecnologia do Rio Grande do Norte. Revista Foco, Vila Velha - Es, v. 9, n. 1, p.251-267, jul. 2016. Semestral. Disponível em: <http://www.revistafocoadm.org/ index.php/foco/issue/view/17>. Acesso em: 03 abr. 2018. 
SOARES, Maurélio; SCARPIN, Jorge Eduardo. Controle Interno na Administração Pública: Avaliando sua Eficiência na Gestão Municipal. Revista de Ciências Jurídicas, Londrina, v. 14, n. 1, p.5-15, mar. 2013. Disponível em: <http://www.pgsskroton.com.br/ seer/index.php/juridicas/issue/view/59>. Acesso em: 19 abr. 2018

TRIBUNAL DE CONTAS DA UNIÃO. Licitações e contratos : orientações e jurisprudência do TCU. 4. ed. Brasília - Df: Tcu, 2010. Disponível em: <www.tcu.gov.br>. Acesso em: 18 out. 2017.

VASCONCELOS, Fernanda. Licitação pública: análise dos aspectos relevantes do Pregão. Prima Facie, João Pessoa, v. 4, n. 7, p.151-163, dez. 2005. Semestral. Disponível em: <http://www.periodicos.ufpb.br/index.php/ primafacie/issue/view/519>. Acesso em: 19 abr. 2018.

ZAGATTO, Thiago Anderson. Inovação nos serviços de limpeza na administração pública - idealismo ou necessidade? Revista do TCU, Brasilia, v. 133, n. 133, p.88-95, ago. 2015. Quadrimestral. Disponível em: <http://revista.tcu.gov.br/ojs/index.php/ RTCU/issue/view/62/showToc $>$. Acesso em: 24 abr. 2018 